\title{
Analisa Video Views to Followers Ratio Instagram pada 6 brand Sepatu Lokal
}

\author{
I Gede Made Pradnya Airlangga \\ pradnya.airlangga@gmail.com
}

\begin{abstract}
Instagram (abbreviated as IG or Instagram) is a photo and video sharing application that allows users to take photos, take videos, apply digital filters, and share them on various social networking services, including Instagram's own. One unique feature on Instagram is cropping photos into square shapes, so they look like the results of Kodak Instamatic and Polaroid cameras. This is different from the $4: 3$ or $16: 9$ aspect ratio that is commonly used by cameras on mobile devices. Instagram can be used on any iPhone, iPad or iPod Touch version with the iOS 7.0 operating system or later, any Android mobile phone with the operating system version 2.2 (Froyo) and above, and Windows Phone 8. This application can be downloaded via the Apple App Store and Google Play. This study aims to find the ratios found on social media Instagram. These ratios can later be used to perform analyzes that can be measured mathematically. The research method used is exploratory to find the variables contained in Instagram. These variables will be juxtaposed to be tested for their relevance so as to find the relevant ratios used to assess the performance of an Instagram account. The results of this Instagram social media research show that there are 14 ratios that can be used to assess, measure and compare the credibility of an Instagram account. The implication of the discovery of this ratio is that further researchers can conduct quantitative research in measuring, assessing and comparing accounts contained on Instagram.
\end{abstract}

\section{ABSTRAK}

Instagram (disingkat IG atau Instagram) adalah sebuah aplikasi berbagi foto dan video yang memungkinkan pengguna mengambil foto, mengambil video, menerapkan filter digital, dan membagikannya ke berbagai layanan jejaring sosial, termasuk milik Instagram sendiri. Satu fitur yang unik di Instagram adalah memotong foto menjadi bentuk persegi, sehingga terlihat seperti hasil kamera Kodak Instamatic dan polaroid. Hal ini berbeda dengan rasio aspek 4:3 atau 16:9 yang umum digunakan oleh kamera pada peranti bergerak. Instagram dapat digunakan di iPhone, iPad atau iPod Touch versi apapun dengan sistem operasi iOS 7.0 atau yang terbaru, telepon genggam Android apapun dengan sistem operasi versi 2.2 (Froyo) ke atas, dan Windows Phone 8. Aplikasi ini dapat diunduh melalui Apple App Store dan Google Play. Penelitian ini bertujuan untuk menemukan rasio - rasio yang terdapat pada sosial media Instagram. Rasio - rasio ini yang nantinya dapat digunakan untuk melakukan analisa yang dapat terukur secara matematis. Metode penelitian yang digunakan yaitu ekploratif untuk menemukan variabel - variabel yang terdapat pada Instagram. Variabel tersebut akan disandingkan untuk diuji relevansi nya sehingga menemukan rasio yang relevan digunakan menilai peforma sebuah akun Instagram yang. Hasil dari penelitian sosial media Instagram ini menunjukan bahwa terdapat 14 rasio yang dapat digunakan untuk menilai , mengukur serta membandingkan kredibilitas dari sebuah akun Instagram. Implikasi dari penemuan rasio ini adalah para peneliti selanjutnya dapat melakukan penelitian kuantitatif dalam mengukur, menilai serta membandingkan akun-akun yang terdapat pada instagram.

Keyword: Media sosial, Instagram, Rasio Instagram, Kredibilitas Akun Sosial Media. 


\section{PENDAHULUAN}

Teknologi informasi dan komunikasi yang telah berkembang dengan pesat mampu menghantarkan manusia untuk menciptakan bentuk baru dalam cara berkomunikasi serta berinteraksi melalui media sosial. Media sosial memberikan pengaruh yang cukup besar, saat ini media sosial diajadikan sarana berkomunikasi dalam setiap aktifitas keseharian bersosial di masyarakat. Komunikasi tidak hanya dapat dilakukan secara fisik, tetapi juga dapat dilakukan dengan menggunakan berbagai aplikasi media sosial di dunia maya. Keunggulan layanan aplikasi sosial media adalah memberikan ruang komunikasi dua arah antara konsumen-perusahaan dan konsumen-konsumen.

Dengan pesatnya perkembangan teknologi media sosial, telah memberikan dampak terhadap situs-situs komunikasi, dari yang awalnya hanya sekedar email dan chatting, saat ini sudah banyak jejaring media sosial yang bisa digunakan sebagai alat komunikasi.Contoh aplikasi sosial media yang memiliki banyak pengguna saat ini yaitu Instagram. Instagram (disingkat IG atau Instagram) adalah sebuah aplikasi berbagi foto dan video yang memungkinkan pengguna mengambil foto, mengambil video, menerapkan filter digital, dan membagikannya ke berbagai layanan jejaring sosial, termasuk milik Instagram sendiri. Satu fitur yang unik di Instagram adalah memotong foto menjadi bentuk persegi, sehingga terlihat seperti hasil kamera Kodak Instamatic dan polaroid.

Hal ini berbeda dengan rasio aspek 4:3 atau 16:9 yang umum digunakan oleh kamera pada peranti bergerak. Instagram dapat digunakan di iPhone, iPad atau iPod Touch versi apapun dengan sistem operasi iOS 7.0 atau yang terbaru, telepon genggam Android apapun dengan sistem operasi versi 2.2 (Froyo) ke atas, dan Windows Phone 8. Aplikasi ini dapat diunduh melalui Apple App Store dan Google Play. Cukup banyak akun perushaan-perusahaan terkenal yang ada pada Instagram, contohnya seperti brand sepatu local buatan Indonesia. Adapun 6 Brand Sepatu local, diantaranya yaitu : vantela, aerostreat, wakai, eagle, footstep footware, Tomkins.

Penelitian ini bertujuan untuk menemukan rasio - rasio yang terdapat pada sosial media Instagram. Rasio - rasio ini yang nantinya dapat digunakan untuk melakukan analisa yang dapat terukur secara matematis. Metode penelitian yang digunakan yaitu ekploratif untuk menemukan variabel - variabel yang terdapat pada Instagram. Variabel tersebut akan disandingkan untuk diuji relevansi nya sehingga menemukan rasio yang relevan digunakan menilai peforma sebuah akun Instagram yang. Hasil dari penelitian sosial media Instagram ini menunjukan bahwa terdapat 14 rasio yang dapat digunakan untuk menilai, mengukur serta membandingkan kredibilitas dari sebuah akun Instagram. Implikasi dari penemuan rasio ini adalah para peneliti selanjutnya dapat melakukan penelitian kuantitatif dalam mengukur, menilai serta membandingkan akun-akun yang terdapat pada instagram.Penelitian ini hanya berfokus untuk menghitung kredibilitas Video Views to Followers Ratio Instagram pada 6 brand Sepatu Lokal 


\section{TINJAUAN PUSTAKA}

Perkembangan bidang teknologi saat ini terjadi begitu pesat. Melalui perkembangan yang terjadi dari waktu ke waktu menimbulkan maraknya aplikasi - aplikasi serta platform media sosial yang bermunculan. Aplikasi yang sangat diminati oleh masyarakat saat ini diantaranya adalah Instagram, Tiktok, Twitter, WhatsApp dan yang lain sebagainya. Seiring berjalannya waktu, aplikasi sosial media tersebut dapat menjadi candu bagi kalangan masyarakat. Tidak hanya kalangan remaja yang menggunakan aplikasi sosial media, orang tua bahkan anak-anak juga aktif menggunakan aplikasi sosial media tersebut.

Instagram sebagai salah satu media sosial yang saat ini menjadi sebuah gaya hidup baru ditengah - tengah masyarakat khususnya dikalangan anak muda yang memakai sosial media dikehidupan sehari-harinya. Instagram merupakan sebuah aplikasi berbagi foto yang memungkinkan pengguna mengambil foto, menerapkan filter digital, dan membagikannya. Instagram berdiri pada tahun 2010 yang didirikan oleh Mike Krieger dan Kevin Systrom yang merupakan pemrogram komputer dan pengusaha internet. Kata instagram sendiri berasal dari kata insta, yang berarti instan, dan Gram yang diambil dari kata telegram (Wikipedia,2017) Penggunaan internet untuk bisnis secara online telah tumbuh dengan pesatnya. Total nilai perdagangan barang dan jasa dunia melalui ecommerce mencapai $\$ 4,3$ trilliun pada tahun 2004. Tingkat pertumbuhan perdagangan via internet dari tahun 2001 hingga 2005 mencapai 68\% di Amerika Serikat, Eropa 91\%, dan Asia 109\%. Menariknya, $85 \%$ dari perusahaan yang melibatkan perdagangan online tersebut adalah usaha berskala kecil dan menengah (Celuch et al., 2007) Muttaqin (2011) mengatakan instagram marketing adalah melakukan aktivitas marketing menggunakan semua fasilitas yang disediakan oleh Instagram dengan tujuan meningkatkan penjualan (sales) dan menjalin komunikasi yang lebih langgeng dengan pelanggan (customer relationship)..

Menurut (Puguh Kurniawan 2017) Konsep instagram marketing menurut Lasmadiarta (2011) adalah menambahkan bahwa kepercayaan adalah hal yang penting dalam melakukan penawaran, melalui Instagram orang dapat membangun kepercayaan dengan menyampaikan pesan berupa informasi-informasi sebagai berikut, Cantumkan informasi tentang profil sebanyakbanyaknya (selama tidak mengganggu privasi) Masukkan alamat dan kontak yang bisa dihubungi, Cantumkan beberapa nama perusahaan rekanan (bila ada), Jadilah member dari halaman orang-orang terkenal, Posting sesuatu yang bermanfaat, Masukkan foto-foto presentasi yang meyakinkan, Penyampaian Pesan.

\section{METODE PENELITIAN}

Penelitian ini menggunakan metode eksploratif kuantitatif untuk mengetahui kredibilitas dari performa akun Instagram 6 Brand Sepatu local di Indonesia. Metode eksploratif merupakan penelitian yang memiliki tujuan untuk melakukan eksplorasi atau memperdalam pengetahuan ataupun ide-ide baru mengenai suatu hal yang baru, guna merumuskan permasalahan secara terperinci (Maryam, Isrok'atun, and Aeni 2016).

Tujuan dari penelitian ini yaitu mengetahui nilai kredibillitas dari performa akun Instagram 6 Brand Sepatu Lokal. Ada beberapa langkah yang harus dilakukan dalam penelitian ini, sehingga mampu menemukan peringkat pertama akun Instagram Brand Sepatu lokak di Indonesia yang memiliki performa terbaik. Langkah-langkah yang dilakukan pada penelitian ini, diantaranya yaitu : 


\section{Melakukan Eksplorasi Pada Website Untuk Menentukan Objek yang Akan Dianalisa.}

Eksplorasi ini dilakukan pada beberapa halaman website yang menyediakan informasi mengenai objek yang akan di teliti. Setelah ekslorasi selesai dilakukan, sehingga ditemukan nama-nama Brand Sepatu lokal di Indonesia yang akan dijadikan objek analisa. Setelah melakukan eksplorasi pada halaman website, maka langkah selanjutnya yaitu mencari nama akun Instagram dari masing-masing Brand Sepatu. Pastikan semua Brand memiliki akun pada aplikasi sosial media Instagram.

\section{Menghitung Nilai Rata-Rata Variable Dari Top 6 Brand Sepatu Lokal di Indonesia.}

Pada langkah ini, peneliti menghitung nilai variable video views dan Followers Ratio. Variabel merupakan sesuatu yang memiliki nilai bervariasi dimana nilai tersebut dapat dijadikan sebagai dasar untuk empat data yang berbeda seperti rasio, skala, ordinal, nominal dan internal (Rankuti 2015). Untuk menghitung nilai rata-rata dari variabel video Views dan variabel Followers Ratio yaitu dengan cara mengambil minimal 10 postingan kemudian di hitung sehingga menemukan nilai rata-rata dari masing-masing variabel.

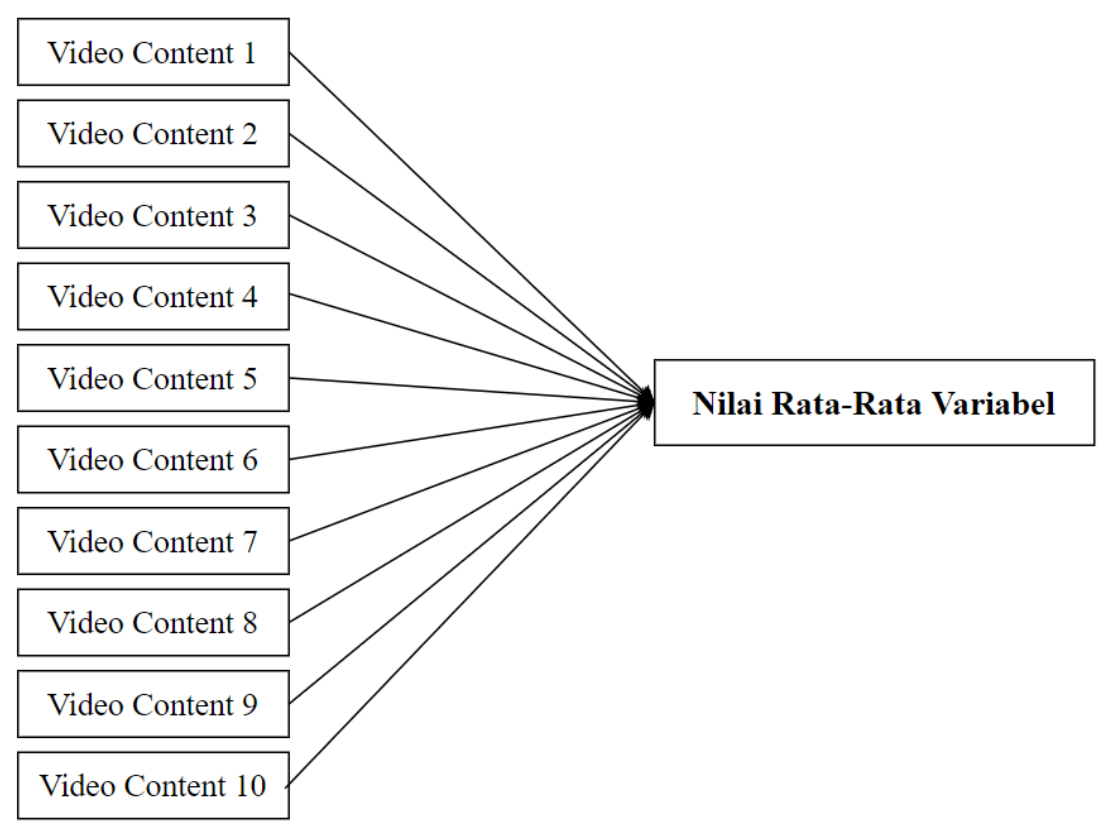

Gambar 1. Analisa Nilai Rata-Rata Variabel.

\section{Menghitung Nilai Kredibilitas Rasio}

Untuk menghitung nilai kredibilitas dari video views to followers ratio, peneliti menggunakan cara membagi nilai variabel pertama dengan nilai variabel kedua. Jika video views memiliki nilai 100 dan followers ratio memiliki nilai 300, maka cara menghitungnya yaitu $100: 300=0,3$. Dengan begitu nilai dari video view to followers ratio adalah 0,3 . 


\section{Menentukan Peringkat Pada Akun TikTok}

Pada langkah terakhir yang dilakukan pada penelitian ini yaitu menentukan peringkat pada masing-masing rasio yang ada. Pada penentuan peringkat perlu melihat karakteristik dari rasio yang di teliti. Jika karakteristik rasio merupakan rendah, maka objek yang memiliki nilai terendah akan mendapatkan angka 5 dan objek yang memiliki nilai tertinggi akan mendapatkan angka 1 . Namun jika rasio memiliki karakteritik tinggi maka objek yang mendapatkan nilai tinggi akan mendapatkan angka 5 dan objek yang mendapatkan nilai terendah akan mendapatkan angka 1. Setelah mendapatkan hasil kredibilitas ratio maka dapat disimpulkan objek yang mana mendapatkan peringkat 1 sampai dengan peringkat 5 .

\section{HASIL DAN PEMBAHASAN}

Akun Instagram dari 6 Brand Sepatu Lokal, diantaranya :

\section{Vantela}

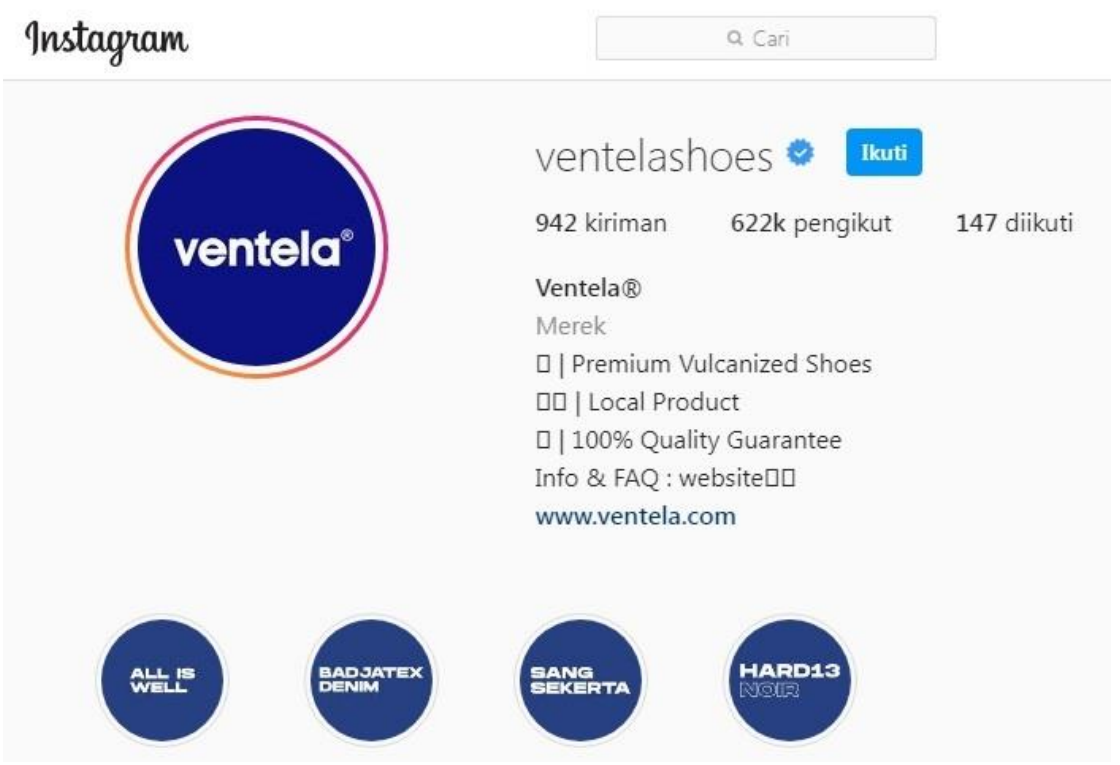

Gambar 1 akun instagram vantela 1

Sumber : https://www.instagram.com/ventelashoes/?hl=id 


\section{Aerostreet}

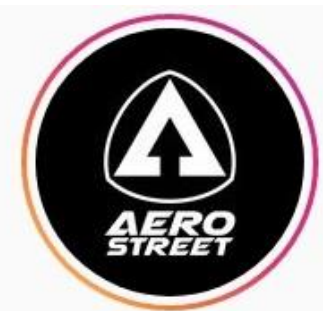

\section{aerostreet $*$ Ikuti}

466 kiriman $\quad 1.8 \mathrm{~m}$ pengikut

38 diikuti

Aerostreet $\mathrm{\square \square}$

\#lokaltakgentar | Katalog lengkap :

-SEPATU : @aerostreet.katalog

- APPAREL : @aerostreet.apprl

口 Official Shop \& Whatsapp $\square$

aerostreet.co.id/ads/marketplace

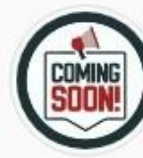

ComingSoon

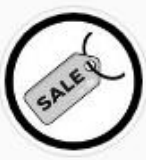

Promo

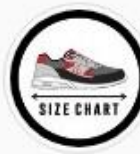

Size Chart

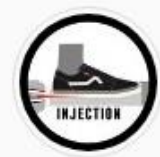

Produksi

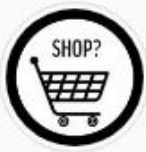

Cara Belanja

Gambar 2 akun aerostrest 1

Sumber : $\underline{\text { https://www.instagram.com/aerostreet/?hl=id }}$

\section{Wakai}

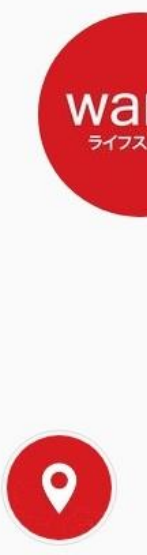

VISIT OIIR

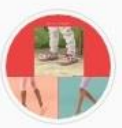

OFFICTAI WA wakaiindonesia * Ikuti

1,288 kiriman $155 \mathrm{k}$ pengikut 70 diikuti

Wakai Indonesia

Toko Alas Kaki

Akun Instagram resmi @wakaishoes @wakaikids berbahasa Indonesia

Twitter: Wakai_ID

Facebook: WakaiIndonesia

Order online di Whatsapp : 0812-8108-9919

linktr.ee/wakaiindonesia
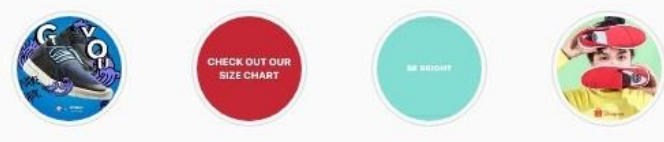

Fuoc $x$ Wakai

CI7F CHART

RRIGHT

ONI INF ৎH

HOME DFII

Gambar 3 akun Wakai 1

Sumber : https://www.instagram.com/wakaiindonesia/?hl=id 


\section{Eagle}

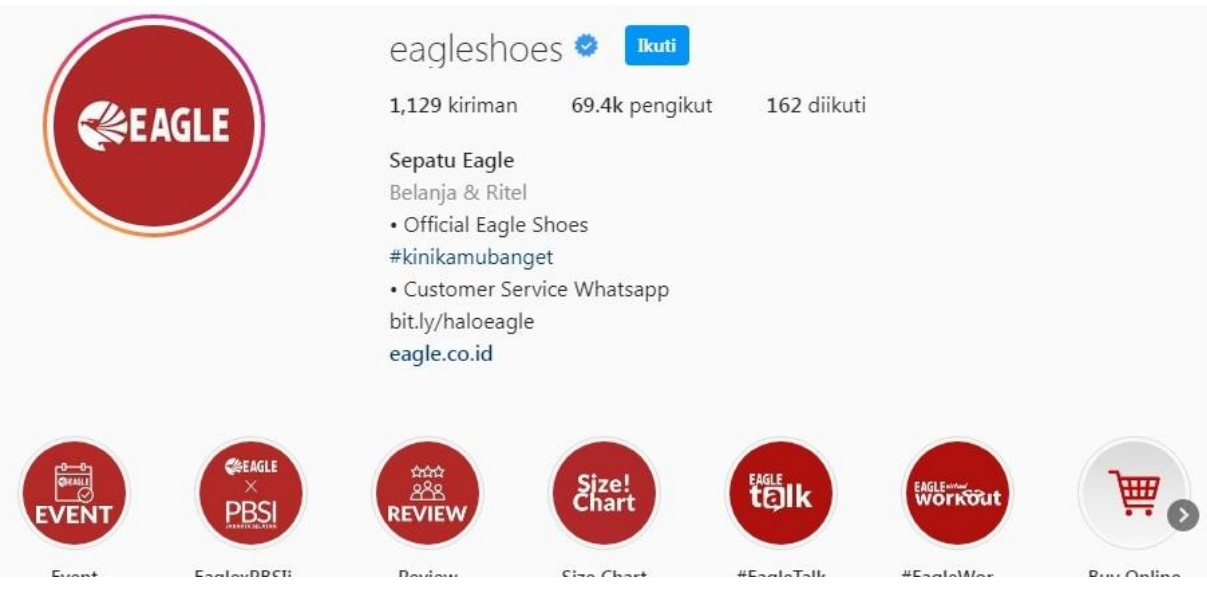

Gambar 4 akun eagle 1

Sumber : https://www.instagram.com/eagleshoes/?hl=id

\section{Footstep Footware}

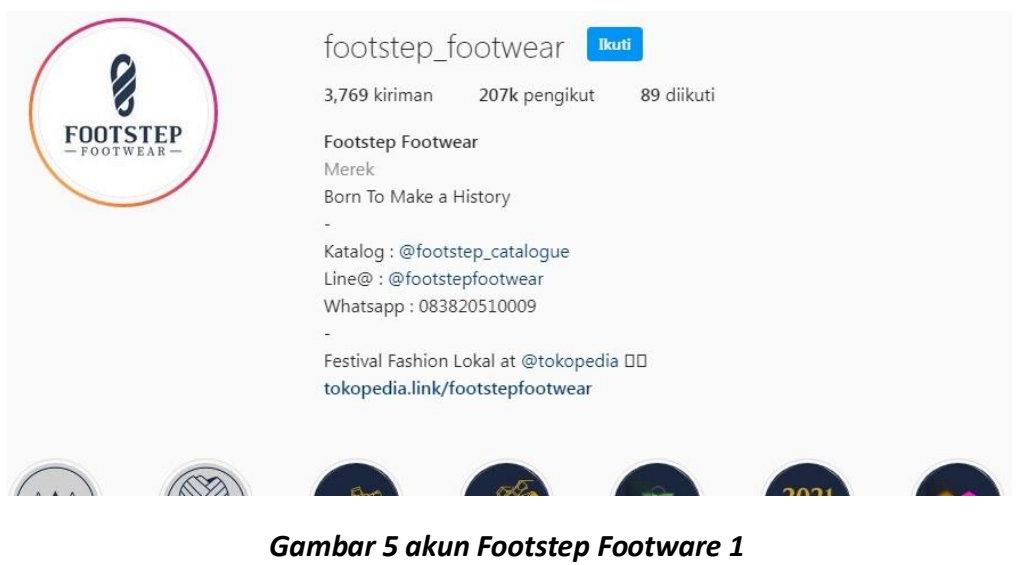

Sumber : https://www.instagram.com/footstep_footwear/?hl=id

\section{Tomkins}

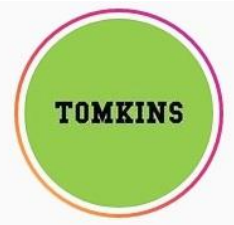

mytomkins * Ikuti

1,649 kiriman $\quad 44.4 \mathrm{k}$ pengikut $\quad 0$ diikuti

TOMKINS Indonesia

Official Instagram account of TOMKINS Indonesia

FB,TikTok,Twitter: @mytomkins

TOMKINS Official di Shopee, Tokopedia, Zalora, Lazada, Blibli, BL \& JD

linktr.ee/tomkins
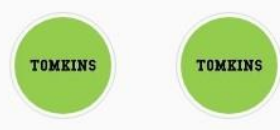

TOMKINS

Store

Online Store

Size Chart

Gambar 6 akun TOMKINS 1

Sumber : https://www.instagram.com/mytomkins/?hl=id 
Dari keenam akun Instagram 6 Brand Sepatu Lokal di Indonesia, peneliti menemukan nilai dari masing-masing variabel yang ada untuk menghitung rasio Video Views to Folllowers ratio dari setiap akun. Pada akun Instagram terdapat 7 variabel, diantaranya yaitu :

1. Likes

2. Followers

3. Following

4. Video Likes

5. Video Comments

6. Video Views

Dari ketujuh variabel tersebut peneliti hanya fokus untuk menemukan hasil dari 2 variabel, yaitu :

1. Video Views

2. Followers Ratio

Dari kedua variabel tersebut kemudian dianalisa sehingga menemukan nilai rata-rata dari variabel video views dan variabel followers ratio. Untuk menghitung nilai rata-rata dari variabel video views dan variabel followers ratio yaitu dengan cara mengambil minimal 10 postingan kemudian di hitung sehingga menemukan nilai rata-rata dari masing-masing variabel. Berikut merupakan tabel nilai rata-rata dari masing-masing brand sepatu local di Indonesia, yaitu :

Tabel 1. Analisa Nilai Rata-Rata Nilai Variabel Video Views dan Followers Ratio Akun Instagram Vantela

\begin{tabular}{|c|c|c|}
\hline No & $\begin{array}{c}\text { Video } \\
\text { Views }\end{array}$ & $\begin{array}{c}\text { Followers } \\
\text { Ratio }\end{array}$ \\
\hline 1 & 101,723 & 617.000 \\
\hline 2 & 137,762 & 617.000 \\
\hline 3 & 227,265 & 617.000 \\
\hline 4 & 117,428 & 617.000 \\
\hline 5 & 72,707 & 617.000 \\
\hline 6 & 112,844 & 617.000 \\
\hline 7 & 149,541 & 617.000 \\
\hline 8 & 134,194 & 617.000 \\
\hline 9 & 115,648 & 617.000 \\
\hline 10 & 108,34 & 617.000 \\
\hline Total & 127,7452 & 617.000 \\
\hline
\end{tabular}

Sumber : Pengolah Data Excel 
Tabel 2. Analisa Nilai Rata-Rata Nilai Variabel Video Views dan Followers Ratio Akun Instagram Aerostreet

\begin{tabular}{|c|c|c|}
\hline No & Video View & $\begin{array}{c}\text { Followers } \\
\text { Ratio }\end{array}$ \\
\hline 1 & 161,551 & $1,800,000$ \\
\hline 2 & 108,1 & 1.800 .000 \\
\hline 3 & 157,766 & 1.800 .000 \\
\hline 4 & 141,962 & 1.800 .000 \\
\hline 5 & 153,727 & 1.800 .000 \\
\hline 6 & 310,282 & 1.800 .000 \\
\hline 7 & 209,41 & 1.800 .000 \\
\hline 8 & 445,871 & 1.800 .000 \\
\hline 9 & 184,722 & 1.800 .000 \\
\hline 10 & 249,194 & 1.800 .000 \\
\hline Total & 212,2585 & $1,800,000$ \\
\hline
\end{tabular}

Tabel 3. Analisa Nilai Rata-Rata Nilai Variabel Video Views dan Followers ratio Akun Instagram Footstep Footware

\begin{tabular}{|c|c|c|}
\hline No & Video Views & $\begin{array}{c}\text { Followers } \\
\text { Ratio }\end{array}$ \\
\hline 1 & 2,991 & 207.000 \\
\hline 2 & 988 & 207.000 \\
\hline 3 & 961 & 207.000 \\
\hline 4 & 1,533 & 207.000 \\
\hline 5 & 957 & 207.000 \\
\hline 6 & 1,642 & 207.000 \\
\hline 7 & 3,027 & 207.000 \\
\hline 8 & 2,172 & 207.000 \\
\hline 9 & 2,025 & 207.000 \\
\hline 10 & 2,126 & 207.000 \\
\hline Total & 292,1516 & 207.000 \\
\hline
\end{tabular}

Sumber : Pengolah Data Excel 
Tabel 4. Analisa Nilai Rata-Rata Nilai Variabel Video Views dan Followers Ratio Akun Instagram Wakai

\begin{tabular}{|c|c|c|}
\hline No & Video Views & $\begin{array}{c}\text { Followers } \\
\text { Ratio }\end{array}$ \\
\hline 1 & 29,029 & 156.000 \\
\hline 2 & 28,126 & 156.000 \\
\hline 3 & 55,183 & 156.000 \\
\hline 4 & 1,293 & 156.000 \\
\hline 5 & 1,314 & 156.000 \\
\hline 6 & 3,569 & 156.000 \\
\hline 7 & 2,048 & 156.000 \\
\hline 8 & 3,919 & 156.000 \\
\hline 9 & 4,562 & 156.000 \\
\hline 10 & 1,901 & 156.000 \\
\hline Total & 13,0944 & 156.000 \\
\hline
\end{tabular}

Tabel 5. Analisa Rata-Rata Nilai Variabel Video Views dan Followers Ratio Akun Instagram Eagle

\begin{tabular}{|c|c|c|}
\hline No & Video Views & $\begin{array}{c}\text { Followers } \\
\text { Ratio }\end{array}$ \\
\hline 1 & 2,007 & 690.200 \\
\hline 2 & 30,902 & 690.200 \\
\hline 3 & 1,473 & 690.200 \\
\hline 4 & 2,696 & 690.200 \\
\hline 5 & 2,005 & 690.200 \\
\hline 6 & 154,72 & 690.200 \\
\hline 7 & 2,073 & 690.200 \\
\hline 8 & 21,425 & 690.200 \\
\hline 9 & 2,28 & 690.200 \\
\hline 10 & 2,461 & 690.200 \\
\hline Total & 22,2042 & 690.200 \\
\hline
\end{tabular}

Sumber : Pengolah Data Excel 
Tabel 6. Analisa Rata-Rata Nilai Variabel Video Views dan Followers Ratio Akun Instagram Tomkins

\begin{tabular}{|c|c|c|}
\hline No & Video Views & $\begin{array}{c}\text { Followers } \\
\text { Ratio }\end{array}$ \\
\hline 1 & 2,231 & 440.400 \\
\hline 2 & 4,043 & 440.400 \\
\hline 3 & 2,931 & 440.400 \\
\hline 4 & 4,843 & 440.400 \\
\hline 5 & 1,241 & 440.400 \\
\hline 6 & 1,157 & 440.400 \\
\hline 7 & 652 & 440.400 \\
\hline 8 & 829 & 440.400 \\
\hline 9 & 835 & 440.400 \\
\hline 10 & 2,485 & 440.400 \\
\hline Total & 233,4931 & 440.400 \\
\hline
\end{tabular}

Sumber : Pengolah Data Excel

Setelah menghitung nilai rata-rata tersebut, maka akan menemukan hasil akhir nilai rata-rata dari variabel video views dan follower ratio

Tabel6. Nilai Variabel Pada Akun Instagram 6 Brand Sepatu Lokal

\begin{tabular}{|c|c|c|c|c|c|c|}
\hline Variable & Vantela & AeroStreat & Wakai & Eagle & $\begin{array}{c}\text { Footstep } \\
\text { Footware }\end{array}$ & Tomkins \\
\hline Video Views & 127,7452 & 212,2585 & 13,0944 & 22,2042 & 292,1516 & 233,4931 \\
\hline Followers Ratio & 617.000 & 1.800 .000 & 156.000 & 690.200 & 207.000 & 440.400 \\
\hline
\end{tabular}

Sumber : Pengolah Data Excel

Pada akun Instagram terdapat 17 rasio yang relevan digunakan untuk mengukur kredibilitas pada masing-masing akun. Namun pada penelitian kali ini hanya berfokus untuk menghitung Video Views to Followers Ratio. Untuk menghitung kredibilitas dari masing-masing akun Instagram setiap Brand Sepatu, peneliti menghitung dengan cara : variabel 1 akan dibagi dengan variabel 2, sehingga ditemukan hasil analisisa dari rasio tersebut. 
Tabel 7. Hasil Perhitungan Rasio Akun Instagram

\begin{tabular}{|c|c|c|c|c|c|c|}
\hline Ratio & Vantela & Aerostreat & Wakai & Eagle & $\begin{array}{c}\text { Footstep } \\
\text { Footware }\end{array}$ & Tomkins \\
\hline $\begin{array}{c}\text { Video } \\
\text { Views To } \\
\begin{array}{c}\text { Followers } \\
\text { Ratio }\end{array}\end{array}$ & 0,00020704 & 0,00011792 & $8,39385 \mathrm{E}-05$ & $3,2171 \mathrm{E}-05$ & 0,00141136 & 0,000530184 \\
\hline
\end{tabular}

Sumber : Pengolah Data Excel

Video Views to Followers Ratio memiliki karakteristik yang tinggi, artinya semakin tinggi nilai yang dihasilkan maka semakin baik kredibilitas dari performa akun tersebut. Untuk memberikan peringkat pada masing-masing Brand sepatu lokal, peneliti memberikan angka 5 kepada brand yang mendapatkan nilai tertinggi dan angka 1 untuk brand sepatu local yang mendapatkan nilai terendah. Berikut merupakan tabel urutan nilai yang dihasilkan oleh masing-masing brand sepatu.

Tabel 8. Nilai Rasio Akun Intagram 6 Brand Sepatu Lokal di Indonesia

\begin{tabular}{|l|c|c|c|c|c|c|}
\hline \multirow{2}{*}{ RATIO } & \multicolumn{5}{|c|}{ NILAI } \\
\cline { 2 - 7 } & Vantela & Aerostreat & Wakai & Eagle & $\begin{array}{c}\text { Footstep } \\
\text { Footware }\end{array}$ & Tomkinks \\
\hline $\begin{array}{l}\text { Video Views to } \\
\text { Followers Ratio }\end{array}$ & 2 & 3 & 6 & 5 & 4 & 1 \\
\hline
\end{tabular}

Sumber : Pengolah Data Excel

Dari Tabel Nilai Rasio Akun Instagram 6 Brand Sepatu Lokal di Indonesia dapat simpulkan bahwa Wakai mendapatkan nilai tertinggi untuk rasio Video Views to Followers Ratio. Sedangkan akun Instagram Tomkins mendapatkan nilai terendah untuk rasio ini. Jadi, pada penelitian ini Wakai memiliki kredibilitas performa yang lebih baik dibandingkan dengan Brand Sepatu yang lainnya. 


\section{KESIMPULAN}

Tujuan dari penelitian ini adalah mengetahui kredibilitas performa dari akun Instagram 6 Brand Sepatu Lokal di Indonesia menggunakan Video Views to Followers Ratio. 6 Brand Sepatu Lokal tersebut diantaranya : Vantela AeroStreat, Wakai, Eagle, Footstep Footware, Tomkins.

Dari keenam brand sepatu tersebut dapat disimpulkan bahwa :

1. Peringkat pertama diraih oleh Brand Sepatu Tomkins dengan nilai terendah yaitu 0,000530184

2. Peringkat kedua diraih oleh Brand Sepatu Vantela dengan nilai 0,00020704

3. Peringkat ketiga diraih oleh Brand Sepatu Aerostreet dengan nilai 0,00011792

4. Peringkat keempat diraih oleh Brand Sepatu Footstep Footware dengan nilai 0,00141136

5. Peringkat kelima diraih oleh Brand Sepatu Eagle dengan nilai 3,2171E-05

6. Peringkat keenam diraih oleh Brand Sepatu Wakai dengan nilai tertinggi yaitu 8,39385E-0 


\section{DAFTAR PUSTAKA}

Maryam, Siti, Isrok'atun Isrok'atun, and Ani Nur Aeni. 2016. 'PENDEKATAN EKSPLORATIF UNTUK MENINGKATKAN KEMAMPUAN REPRESENTASI MATEMATIS DAN KEPERCAYAAN DIRI SISWA.” Jurnal Pena Ilmiah 1 (1): 55160. https://doi.org/10.23819/PI.V1I1.2984.

Puguh Kurniawan. 2017. "Pemanfaatan Media Sosial Instagram Sebagai Komunikasi Pemasaran Modern Pada Batik Burneh Puguh Kurniawan Universitas Trunojoyo Madura." Kompetensi 11 (2): 217-25.

http://journal.trunojoyo.ac.id/kompetensi/article/view/3533.

Rankuti, Freddy. 2015. "Buku Riset Pemasaran.” 2015. 